\title{
EL CUERPO CULPABLE EN EL ESPACIO PÚBLICO: DE DISIDENCIAS, TRAICIONES Y ARREPENTIMIENTOS EN LA CONVIVENCIA VASCA
}

\author{
Adriana M. Villalón ${ }^{1}$ \\ ${ }^{1}$ Universidade Estadual de Campinas, Campinas, SP, Brasil
}

\section{Presentación}

"Ahora matar es contra la ley, aun atacar a alguien. Es prohibido. Todo está cambiando, el tiempo cambia" (Theidon 2004: 14).

En este artículo, analizo aspectos de las micropolíticas y de las narrativas en tensión que eclosionan en el actual proceso de paz vasco (España), ${ }^{1}$ el cual empieza a configurarse discretamente en acciones de revisión social e institucional hacia inicios del año 2000, y gana más fuerza desde el 2011 con el anuncio del cese de acciones armadas de la organización ETA (1959-2018), disuelta en 2018. Tomo como base del análisis las resonancias conflictivas en torno a la figura de algunos ex militantes de ETA (exetarras) ${ }^{2}$ : hombres y mujeres que abandonaron esa organización armada tras una autocrítica de sus actos de violencia, declarándose disidentes ${ }^{3}$. Estas personas participaron, además, de reuniones con sus víctimas con la ayuda de un mediador, organizadas entre los años 2011-2013 por el Gobierno vasco, bajo el nombre de "Encuentros Restaurativos" (ER). ${ }^{4}$

Es así como, en esta era de las disculpas y de las víctimas (Brooks 1999; Blatz 2009; Wieviorka 2003), la sociedad vasca está siendo interpelada a ingresar en una nueva etapa para identificar y gestionar violencias realizadas y sufridas en las últimas décadas. Proceso que cada vez se amplía más en cuanto a períodos, profesionales, responsables y víctimas (del franquismo, de la ex organización armada ETA, del Estado y de agrupaciones parapoliciales), dado que lentamente se visibilizan otras violencias que nunca habían sido tratadas como tales, ni los afectados como víctimas. ${ }^{5}$ Es 
decir, comienzan a apreciarse ciertas reacomodaciones de roles vinculadas a las formas jurídicas de designar los hechos que podrían admitir, por ejemplo, que algunos considerados terroristas se tornen también víctimas, esta vez, de la "violencia estatal, policial" como se recoge en el decreto del Gobierno vasco de "Víctimas de Motivación Política" (Decreto 107/2012). Este decreto los suma a las víctimas de ETA que sólo fueron reconocidas como tales en la Ley estatal "32/1999 de solidaridad con las víctimas del terrorismo", promulgada décadas después de sus familiares ser muertos. ${ }^{6}$ Esos nuevos movimientos generaron algunas resistencias y competencias a aceptar nuevas víctimas, principalmente si entre ellas hay ex victimarios (Chaumont 2000; 2002, Vecchioli 2001). ${ }^{7}$

Otra novedad de este escenario transicional (Castillejo-Cuéllar 2017) ha sido que se empiece a hablar de cierta responsabilidad ciudadana por tolerancias y complicidades con la violencia vivida, ya que se valora que ha habido abandono social e institucional de las personas afectadas por los enfrentamientos. Como, por ejemplo, muestra la literata Edurne Portela (2016) sobre el País Vasco cuando señala que es una sociedad donde la mayoría no sufrió los efectos de atentados, de extorsiones, o asesinatos, etc., sino que más bien ha sido un testigo silencioso de los eventos (por congeniar, por temor o por cobardía).

Es en este sentido que este proceso hace una fuerte apuesta por desenvolver herramientas para inculcar nuevas emociones y nuevas formas de percepción e interacción local. Concientizar, tolerar, convivir, reenfocar resentimientos, empoderar y generar empatía hacia las víctimas, se hace más posible a través de programas específicos del Gobierno local: "Víctimas Educadoras", "Encuentros Restaurativos", así como exposiciones, jornadas y charlas (Irazusta et al 2017a), o a través de entidades financiadas por el mismo. Así, estas actividades, que pude etnografiar, enmarcadas por las categorías de normalización y convivencia (Villalón 2016) ${ }^{8}$, promueven acciones tales como reconocimientos del daño causado; exposición de testimonios de víctimas (de diversas violencias) y de exetarras; encuentros entre ciudadano/ as comunes, agentes educativos y/o políticos. De esa forma, se busca pasar de coexistir a convivir.

El texto se basa en registros etnográficos que realicé en el marco de una larga investigación en el escenario vasco (España) acompañando inicialmente la construcción de la vasquidad a través de su política, lingüística y movimientos nacionalistas (Villalón 2011; 2016), para centrarme, actualmente, en el vigente proceso de paz (Irazusta et al 2017a,b). En la primera parte del texto presento ejemplos de exetarras y sus rupturas con la organización ETA y con sus prácticas. Utilizo entrevistas, material de 
prensa, una tertulia radial y observaciones que realicé durante los eventos diversos que expliqué arriba. Destaco de esos exetarras los meandros que adquieren sus narrativas cuando, desde estilos lingüísticos más apropiados, ensayan una mudanza de eje que reinscribe las prácticas de sus cuerpos responsables - antes amparadas en un significado político-, en el campo de las moralidades del daño, del perdón y de la empatía con las víctimas. Coloco en diálogo esos movimientos con las reacciones generadas entre sus familiares, ex compañeros y medios de comunicación que leyeron esas disidencias como arrepentimientos y/o traiciones. Esto implicó que esos ex militantes tuvieran que enfrentarse con perder redes de apoyo y recalibrar sus narrativas vitales al salir del rol de sufrientes que sacrificaron sus vidas por luchar por Euskal Herria y contra la opresión de los Estados español y francés, relato que antes los amparaba y de hecho aún sustenta los argumentos de muchos militantes, etarras, políticos y familiares.

En la segunda parte, analizo el espacio donde se inserta la construcción social de estos exetarras críticos y su participación en los "Encuentros Restaurativos" (ER), en los que, ayudados por un mediador, no sólo se reunieron con los familiares de las personas que mataron, sino que, lo principal, hicieron pública su ruptura con la violencia. La demanda de hacer esos encuentros fue de los propios militantes, cuando aún estaban presos. El formato y contenido fueron del Gobierno vasco y expertos académicos. ${ }^{9}$ Analizo estas actividades en diálogo con lecturas que, más que apostar por convivencias, como las que intenta construir el Gobierno, traen otras emociones al campo de gestión de procesos de post violencia. Así, al tiempo que rechazan las disculpas como opciones insuficientes, validan los resentimientos y las "coexistencias contenciosas" (Payne 2009). A lo largo del texto también traigo experiencias nacionales que han experimentado situaciones de conflictos internos que tienen puntos en común y diferencias con el caso vasco, sin menospreciar las particularidades de su inserción en sus contextos locales. En las palabras finales, enfatizo la importancia de mostrar la complejidad de las facetas que recorren estas situaciones para así poder comparar y pensar otros casos.

A través de estas descripciones etnográficas, otras cuestiones que guían mi análisis son: ¿Cómo se acomodan palabras, emociones y cuerpos culpables en espacios públicos que demandan disculpas y autocrítica? ¿Cómo se insertan estas rupturas de ex militantes armados que reconocen sus crímenes en un campo de relaciones configuradas en torno a conceptos como traición y heroísmo? ¿Cómo interaccionan en sus comunidades las distintas figuras implicadas, directa o indirectamente, en los conflictos? ¿Cómo se trasladan al espacio local vasco los dispositivos de gestión de posconflictos consagrados internacionalmente? 


\section{De cuerpos inculpados: atravesando el espacio público}

"Cómo dirimimos el hecho de que el exterrorista vuelve a la sociedad, a una sociedad que en parte le acoge como héroe y en parte le rechaza como monstruo. [...] Si pensamos que para algunos el terrorista es un ser abominable y para otros un héroe, ¿̇cómo conseguir una convivencia pacífica post ETA? [...]“ (Portela 2016: 143).

Aniversario, cementerio, rostros, nerviosismos y claveles. Un rostro tenso suavizado por unas flores condensa la aparición pública de un ex miembro de ETA que decidió presentarse en el acto del $14^{\circ}$ aniversario de muerte de una de sus víctimas. Trece de los claveles que llevaba eran rojos y sólo uno blanco, simbolizando el tiempo transcurrido desde el asesinato y su relectura de sus actos de violencia, según narra la nota de prensa ${ }^{10}$. Su visita estaba previamente acordada con la viuda del difunto, pues era necesario que la presencia de su cuerpo culpable contara con "[...] la disposición de otros cuerpos para hacerle un lugar" (González 2014: 105). Aun así, el "habitus del cuerpo al caminar, respiración, ritmo de la marcha, balanceo de los puños..., adelantamiento del tronco..." (Mauss [1950] 1979: 350) de ese exetarra estarían perturbados. ¿Cómo se mueve una persona con delitos de sangre a sus espaldas, cómo encaja en un espacio público atento a sus movimientos?

La singularidad de este ex militante radicaba en que había rechazado la violencia que realizó como etarra y pasó a integrar el grupo de "presos comprometidos con el irreversible proceso de paz"11. Decisión tomada años después de estar cavilando y sopesando, entre rejas, posibles estigmas y consecuencias políticas, vecinales, familiares y... vitales. Sabía que sus actos tendrían un precio y que incomodarían a aquellos que sienten que ellos "no se debilitaron", como me afirmó otro etarra que entrevisté estaba muy contrariado con esa línea de arrepentidos. Este hombre, abogado de formación, cuestiona lo que llama "salidas ruidosas" de sus ex colegas, preferiría que hubieran salido de ETA "por la puerta de atrás y calladitos" (entrevista F.E, marzo 2017). Lo entrevisté en la sala donde gestiona atención y orientación para ex presos de ETA, sin distinción, en la búsqueda de empleo y vivienda.

El proceso de cuestionar la violencia desde nuevas moralidades no era algo sencillo, si bien iba tomando forma en los pensamientos, estos no siempre se traducían en palabras ni hallaban el momento adecuado de expresarse, como me explicaba otro de estos exetarras: "cuando nos juntábamos en el patio de la cárcel, sólo dos hablaban dando directivas... y el resto escuchábamos callados" (entrevista I.R, marzo 2017). Les disuadía el 
temor al vacío o a poder recibir un tiro de gracia de sus iguales por ser, como todos, algo así como un archivo viviente, como expresaba un pistolero desde otro escenario (el brasileño) cuando también sopesaba los riesgos de dejar su comunidad de iguales:

“[...] si estás dentro no intentes salir, si estás afuera no pretendas entrar. Porque es peligroso. Porque si yo quisiera salir ahora que tengo 45 años, duraría poco. Porque ellos mismos intentarán 'quemar el archivo' para silenciarme y que yo no diga nada" (Barreira 1998: 83, mi traducción).

Este autor y su personaje, si bien remite a otras prácticas, permite dialogar con las lógicas que podrían tener quienes lidian con asesinar personas, independientemente de cómo ellos expliquen sus motivos (políticos, honra, venganza, trabajos, etc.). ${ }^{12}$

Con todo, ese mismo exetarra pasaría del temor a hablar, a publicar un libro autobiográfico titulado "Lo más difícil es perdonarse a uno mismo" (Rekarte 2015). El libro abre con recursos narrativos conocidos que presentan al autor en una situación vital compleja como el haber tenido algún familiar que sufrió torturas durante la transición española en el post franquismo (1975-1982), así como cierto paso por el consumo de drogas, que trasluce victimización y explicación tácita del camino de lucha armada escogido. Tanto él como otros ex militantes, presentan sus relatos sobre prácticas comprometedoras pasadas en narrativas en primera persona, como las publicadas en entrevistas en periódicos y libros ${ }^{13}$. Este libro en concreto generó mucho rechazo entre sus ex colegas de armas porque describe sus prácticas en una serie de acciones que presenta como una mezcla de casualidades y sinsentidos. En su narración, el matador pasa a ser, no el gudari (soldado) ${ }^{14}$ que se sacrifica por la causa vasca y con años de cárcel encima, sino un joven sin rumbo que entró en la lucha armada por mera ingenuidad, que quiso darse importancia o se sintió presionado por la reclamación local vecinal que les gritaba "ETA, imátalos!" (Alcedo Moneo 1996). Entrevisté a este hombre en el pueblo vasco donde aún estaba acabando de pintar un nuevo bar que iba a abrir, tras fracasar con otro anterior en un sitio diferente. Esto último lo atribuía a la virada de espaldas que recibió por ser un arrepentido y por sus críticas a ETA en su libro, pero se reafirmaba diciendo: "Sí, soy un arrepentido ¿̇y qué?".

Tanto este hombre, como aquél con quien abrí este texto que se lanzó casi en solitario al cementerio, participaron de actividades vinculadas a los nuevos espacios de gestión de la pacificación, animados desde el Gobierno vasco. Me refiero, como mencioné antes, a los "Encuentros Restaurativos" que consistieron en un encuentro cara a cara entre víctimas y responsables 
(directos o no) de las muertes de sus familiares, unos para obtener explicaciones y otros para asumir responsabilidades y/o aliviar culpas, ayudados por un mediador que describo más en la segunda parte de este texto. De hecho, aquel día fúnebre cuando se expuso con el ramo de claveles, el hombre contó con el auxilio de una mediadora.

De los más de 900 integrantes de ETA, sólo expresaron su ruptura crítica con ésta y sus prácticas, alrededor de una treintena y, además, los "Encuentros Restaurativos" con sus víctimas no fueron muy numerosos; aun así esos actos tuvieron bastante repercusión social y mediática. De ese modo, tanto la categoría de arrepentidos instaurada desde los medios, como la de traidores desde sus ex allegados, rápidamente fueron naturalizadas e instituidas no sólo en el ámbito institucional y de la prensa sino en el social. Fue alto el precio pagado por salir del rol del militante que se sacrifica por Euskal Herria y por asumir que las acciones ${ }^{15}$ fueron asesinatos. Esto dejó arrinconada la categoría de disidentes que para algunos de estos ex militantes tiene más sentido y protección. Es en ese sentido que esta nueva situación eclipsa los tres adjetivos que se intercalan según el contexto: arrepentido, disidente y traidor, sin tener ninguno un único significado.

Como se ve en estos ejemplos, los exetarras son heterogéneos, difieren en su revisión de los hechos de violencia, en los años de participación en ETA y en las responsabilidades y tipos de delitos. Algunos se auto consideran intelectuales o más reflexivos que otros a quienes acusan de sólo buscar obtener permisos carcelarios; así como no todos apostaron por hacer declaraciones públicas, ni dieron entrevistas. ${ }^{16}$ Tienen en común el hecho de que, esta figura local de exetarras, sentenciados como arrepentidos y traidores reconfigura divisiones locales, genera movimientos y disputas al igual que otras categorizaciones, de otros ámbitos de violencia con las que dialoga. Por ejemplo, conversa con la situación de los "(des)vinculados" en el "fin del conflicto armado colombiano", nombre institucional que reciben jóvenes que realizaron actos de violencia y además están reconocidos como víctimas por haber sido captados siendo adolescentes. Ellos están atravesados por conceptos de héroe y víctima, al tiempo que son rechazados por las víctimas de las comunidades adonde retornan como "desvinculados", entre otras problemáticas (Theidon et al 2006; Hoyos 2011; Olaya Góez 2018). ${ }^{17}$ Ya desde otro espacio, el del post senderismo peruano, Carlos Agüero (2015: 48) quien se presenta como hijo de militantes de Sendero Luminoso, trae el

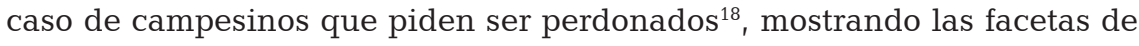
los arrepentimientos y sus contradicciones (victimario, víctima, arrepentido, repudiado) en una misma persona. Tensiones que él mismo, como hijo de senderistas, también alberga. Traigo aquí estos ejemplos de otros escenarios 
nacionales para pensar su aproximación con otras rupturas internas que también representan, así como las duras reconfiguraciones que acarrean al abandonar las lógicas que justificaban sus crímenes.

Entonces, retomando esta figura crítica, quiero señalar también que su situación no es la habitual del espacio penal donde se delata o cuenta la "verdad" a cambio de reducción de condena. Es decir, ellos no se sienten forzados a decir la verdad para anticiparse a la posibilidad de que su nombre surja entre los testimonios de las víctimas o a ser delatado por otros, como ocurrió, por ejemplo, con los victimarios sudafricanos (Hilb 2014) ${ }^{19}$. Tampoco como los paramilitares colombianos que de hecho ya están juzgados y presos (Castillejo-Cuéllar 2013). Se trata de otro tipo de motivaciones vinculadas a la trama de agencias individuales que aspiran tanto a tejer una biografía más liviana e íntegra para circular por el mundo para descubrir la dignidad de la vida humana, la de sus víctimas y la propia; como a proteger sus intereses políticos que se ven alterados en los estigmas de arrepentidos y traidores. Así repasan sus acciones desmembrando militancia de juicios morales.

En esa línea de fragmentaciones intentaba moverse otro "disidente" desde un espacio radial. Era el mes de julio del año 2014 y por primera vez, yo diría, se escuchó en el País Vasco en la conocida Cadena Ser, un etarra crítico y una víctima como invitados, guiados por un presentador. ${ }^{20}$ Las tres narraciones de los participantes de esa tertulia, a pesar de intentar mostrar cierta confluencia de intereses, se cruzaron, pero no se encontraron.

"-Ha matado, ha secuestrado, ha puesto coches bomba y ...", de este modo el periodista introducía, en el espacio radial, a uno de los participantes, al tiempo que buscaba que emitiera palabras que demostraran el "-recorrido personal que ha hecho para reconocer todo el daño que ha causado...". Se trataba de otro preso disidente, ex dirigente de ETA, que había usado un permiso de salida para hablar ante los micrófonos. Por momentos, los desencuentros entre ambos me recordaron a un personaje de Borges que investiga una serie de crímenes, cuando sus palabras son alteradas por un periodista que quiere llevarlo a su terreno:

“[El redactor...] quería hablar del asesinato; Lönnrot prefirió hablar de los diversos nombres de Dios; el periodista redactó en tres columnas que el investigador Erik Lönnrot se había dedicado a estudiar los nombres de dios para dar con el nombre del asesino. Lönnrot, habituado a las simplificaciones del periodismo, no se indignó..." (Borges 2010 [1944]: 603).

Por su parte, el otro tertuliano invitado era una víctima de terrorismo que se había tornado tal tras la muerte de su padre a manos de ETA. Era una de las tantas víctimas que, como dije, sólo fueron reconocidas como tales 
años más tarde del asesinato de sus familiares (Ley estatal 32/1999). Ese hombre también se había reunido en la cárcel con un exetarra -en el marco de los "Encuentros Restaurativos"- con una curiosidad principal la de saber "cómo hacían para matar". Destacó que deseaba confirmar su hipótesis de que si alguien mira a los ojos cuando va a matar a alguien, sin duda el cruce de miradas detendrá la decisión letal. Pues desde una inquietud inspirada en Levinas (2010) consideraba que "en la mirada se encuentra la humanidad". Pero la respuesta que expuso el exetarra sobre secuestros y acciones eludiendo nombrar muertes, acabó desconfirmando la hipótesis de la víctima. ${ }^{21}$ Pues narró un caso intentando mostrar humanidad, la suya, para explicar que le resultaba difícil realizar la acción (mortal) cuando veía que sus objetivos eran personas. Para ilustrar eso, relata el secuestro que hicieron de un empresario y cómo tras la convivencia con el mismo, y con su mirada, experimentaron sentimientos encontrados: "-ahí vimos que ya no era una acción sino una persona...". ${ }^{22}$

Así, los pensamientos e intereses de ese hombre no estaban al cien por cien con lo que ese encuentro radial exhortaba, pues se encontraba aún, pensando en voz alta, poniendo en orden ideas, eventos y sentimientos. Es decir, esa figura del preso arrepentido que se estaba creando y que inmediatamente era vinculada a valores y acciones concretas, chirriaba ante algunas respuestas o movimientos inesperados que escapaban del protocolo y que, rápidamente, eran ignorados para mantenerlo en el papel al que fue convocado. Aun así, tanto este hombre como otros en situación de testimoniar (ya sea en un modelo factual judicial, una audiencia pública, etc.), consiguen filtrar en esos formatos, otros temas que quieren enfatizar en su elaboración, de que los hechos de sangre sufren una redimensión de sentidos al ocupar el espacio público. Así como se valen del recurso a metáforas y elusiones para narrar asesinatos en su fragmentada asunción de responsabilidades. Es decir, el testimonio radial de ese hombre podríamos situarlo entre, por un lado, el análisis de Pollak (2006: 59), que, hablando de víctimas del nazismo y sus posibilidades de expresarse, marca cómo cada testimonio se sitúa en el espacio de lo decible: "de gestión de la identidad, que resultan del trabajo de acomodamiento al mundo ordinario [...a] la dificultad para hacer coincidir el relato con las normas de la moral corriente". Y, por otro, como conectado con otra dimensión de estos procesos que describe Castillejo-Cuéllar en el marco del proceso de Justicia y Paz colombiano: las tergiversaciones que los propios victimarios pueden hacer en su favor. Esto es, cuando a cambio de contar la "verdad" esas figuras paramilitares reciben reducción de condenas:

“[...] se sabe que son escuchados, que sus movimientos son observados, [...] que se pueden inculpar o traicionar. El arte de versionar radica en el control y 
la administración de la palabra, incluso cuando el objeto es dejarla libre en una turbulenta emanación de hechos" (Castillejo-Cuéllar 2013: 26),

Se aprecia así el juego del lenguaje donde los propios victimarios regulan sus confesiones. Retomo esta cuestión de los testimonios en el próximo subtítulo.

Para cerrar el programa, el presentador, con ese mismo espíritu de traducir y orientar el relato, lanza al invitado una pregunta íntima que requeriría una revisión vital profunda: " -iHas pensado en cómo habría sido tu vida si no te hubieras subido al tren de ETA?"; pero las exigencias del ritmo del directo radial sobreentienden que no habrá tal análisis. Aun así, el preso reenfocando su vida, calibra sus palabras, al tiempo que enfatiza sus preocupaciones y responde "-No le doy muchas vueltas, mi familia ha sufrido, ha sido complicado..."; insinuando un deseo de centrarse en sí mismo, sin hacer una reflexión en negativo de su vida pasada como parecía esperar el locutor.

En otro momento de la tertulia, este exetarra preguntó a los presentes y a la audiencia radial "-¿Qué sucederá cuando los presos acaben sus condenas y regresen a sus pueblos natales?, ¿Cómo vamos a convivir todos juntos?". Cuestiones significativas en los pequeños municipios vascos que suelen ser punto de confluencia y fácil encuentro, deseado o no, entre vecinos y, en este caso, entre ex compañeros de armas y sus víctimas. A pesar de la densidad de la pregunta esta no fue recogida durante la tertulia ni por el presentador ni por el otro invitado. El ex militante se la respondió a sí mismo y con frases casi incompletas anticipó cierta posibilidad de encuentros ambiguos: "-la gente los va a recibir [a los ex presos] normalmente...", afirma, " -no por lo que han hecho, hay gente que está en contra..., pero es la vecina, es el hijo de alguien que conoce". ¿Cuál es la intimidad, en los términos de Herzfeld (1997) a la que retornan esos integrantes de ETA (críticos o no), tras cumplir condena? Se vuelve a un espacio de relaciones estrechas, tensadas por distintas divisiones que recién ahora son cuestionadas. Tal como dice ese hombre, unos y otros se conocen, "es el hijo de...", aspecto que ya había señalado la antropóloga vasca Begoña Aretxaga: "the murderer is not a stranger, nor a cultural other but the next door neighbor" (2005: 166). Refiriéndose a la cercanía y estrechez de las relaciones sociales que atraviesan ese espacio local que ella contraponía a la imagen que se construye en USA sobre la figura del "terrorista musulmán" como un ser desconocido y temido.

Otra faceta de las tolerancias y sospechas acerca de lo que estaba pasando entre la población de pueblos y ciudades vascas, la aporta una nueva narración de Agüero (2015) sobre su barrio del Perú senderista: 
“Cuando vivíamos en El Agustino nuestros vecinos próximos sabían perfectamente qué hacían mis padres y qué pasaba en mi casa. Los vecinos de la cuadra y la siguiente, lo sabían más pero sin detalles. Los del barrio lo sospechaban. Las opiniones eran variadas, la solidaridad y el pequeño apoyo, la discreta simpatía por los que luchaban por 'la justicia' y la crítica que prefería mantenerse en voz baja por temor al Partido. Es raro, pero también era claro que nosotros sabíamos que infundíamos temor y lo usábamos para protegernos" (Agüero 2015: 28).

Esta descripción permite preguntar cómo funcionan estas proximidades en otros lugares y en el espacio local. En ese sentido, sentí claramente la dimensión de esta expresión de Agüero (Ibid) "...los vecinos [...] lo sabían", junto con la pregunta del militante teturliano: “¿qué pasará cuando regresen...?", cuando estuve entrevistando a aquella viuda que recibió al otro exetarra en el cementerio. Esta mujer además de ser víctima ha sido directora de la "Oficina de Atención a las Víctimas del Terrorismo del Gobierno vasco" entre 2009 y 2012, participó de los "Encuentros Restaurativos" y es afín a la reinserción de ex militantes que han realizado una reflexión crítica. ${ }^{23}$ Sus pensamientos y aplomo impactan a unos y otros. Cuando hablé con ella, en su pequeño pueblo vasco, me destacó las emociones contrapuestas por la superposición de lazos de amistad, enemistad, culpabilidad y victimización que conformaban una red sofocante en los espacios de violencias realizadas, sufridas y festejadas (Entrev M.L marzo 2017). Ella conoce unos y otros, percibe quien la esquiva, quien se acerca a dar un saludo, quien intenta mantenerse neutro. ${ }^{24}$ Se trata de una intersección de vínculos como los que retrata Aramburu (2016) en su premiada novela Patria cuando presenta casos de matadores y víctimas que tenían lazos previos familiares o de amistad. ${ }^{25}$ Es decir, serán numerosas las situaciones cercanas que van a requerir que las narrativas de violencias sean cuidadosamente gestionadas, midiendo resentimientos, sospechas y rabias acumuladas. Tal como desde otro espacio nacional muestra la etnografía de Das (1999: 133) cuando describe reuniones familiares y vecinales punjabi buscando equilibrio sobre un mar de fondo dañado en el honor, pureza y roles femeninos. Mujeres que sufrieron rapto y violación a manos de sus enemigos durante la partición de la India (Jimeno 2008: 271). ¿Cómo reconstruir y rehabitar el mundo tras determinadas situaciones de violencia?. En definitivo, todos esos autores muestran que es necesario para abordar esas problemáticas de conflictos y sus sufrimientos, considerar los lazos que tienen con lo "...moral, cultural and political" (Kleinman et al 1997: XXV).

Desde luego que estas situaciones de proximidad entre las partes enfrentadas no son exclusivas del País Vasco, podemos encontrar casos de enfrentamientos, con muertes, entre personas cercanas (amigos, vecinos, 
familiares) en diversos espacios nacionales. Por ejemplo, casos de guerrilleros desaparecidos cuyo tío paterno participó de la ESMA, en Argentina (Arenes et al 2016) o las terribles guerras internas de Ruanda entre vecinos, amigos y/o familiares (Mamdani 2001), memoria que se busca diluir en la discutida frase gubernamental "somos todos ruandeses". Sin duda la lista puede ampliarse a muchos lugares más, como la ex Yugoslavia (Bessone, Blach 2018) o como se ve en el film Before de Rain (1994) ${ }^{26}$; donde es habitual encontrar en la gestión gubernamental del "post", demandas para recuperar la convivencia, la tolerancia, la unidad y una sanción de políticas que acaban siendo injustas porque no logran abarcar todo el daño sufrido.

Cierro este punto agregando a ese mar intricado de adhesiones y rechazos, otro ejemplo que muestra que tanto los exetarras disidentes como sus los familiares deben administrar nuevas situaciones (de amenazas, acosos) que tal vez antes, ellos mismos provocaron en otros. En ese sentido, la ex pareja de un arrepentido me narraba: " - Nos hacen el vacío... gente íntima que te retira el saludo, no te dicen nada, no te miran, se cruzan de acera" (entrevista M.A, febrero 2017). Esta mujer tanto siente una falta de espacio adonde ir, como vive como una maldición la consagración de la palabra arrepentido pues cree que no le hace justicia a la disidencia a la que llegó su pareja tras una larga reflexión, según ella narra con admiración. Con todo, juegan aquí las lógicas del reconocimiento que se desprenden de las identificaciones atribuidas por los otros. Ser reconocidos como nuevas víctimas o disidentes críticos requiere contar con la capacidad de poder ser escuchados (Pollak 2006); y además, ser recibidos y contemplados de ese modo por los otros miembros de la comunidad política.

Las políticas de gestión no llegan a estas micro situaciones donde las personas se debaten entre reprimir o dar rienda suelta a sus sentimientos, sufrimientos y narrativas que se desencuentran y/o coexisten en tensión.

\section{De restauraciones y normalidades}

“- ¿Uno siente vergüenza?

- Pues yo salgo de permiso y a mí me da corte que me vean y lo pasen mal, que sufran, que digan: '14 años y este capullo paseándose por la calle'" (Entrevista con ex militante, Diario El Mundo 20-9-2015). ${ }^{27}$

Estos exetarras, como vengo diciendo, participaron de los "Encuentros Restaurativos" (ER) entre integrantes de ETA y víctimas, organizados por 
el Gobierno vasco. Parte de las emociones que los estructuraron no fueron fortuitas, provinieron de unos procesos previos que restringieron otras posibilidades. Ingresar a "ER" tuvo algunos requisitos tanto para víctimas como para etarras, fue preciso realmente querer participar y superar condiciones. Así, la abogada-mediadora que los coordinó, Esther Pascual Rodríguez, se entrevistó con todas las personas interesadas para poder sondear y sopesar sus intereses reales sobre por qué querían encontrarse unos con otros. Ella evaluó si esas personas estaban listas para enfrentarse. Tuvo en cuenta tanto que el discurso sobre los delitos por los que estaban detenidos no fuera reivindicativo, como también que los exetarras no estuvieran tan quebrados emocionalmente y no pudieran soportar las preguntas de la víctima. La víctima, a su vez, no podía ir en actitud vengativa, ni estar con sus duelos mal resueltos, debía estar en condiciones de enfrentar ese encuentro. No obstante, ambos participantes debían obtener algo en común, como se aprecia en el objetivo dado a esta iniciativa, que era el de crear un vínculo a partir del dolor, sea sufrido, como generado, así como explica en su libro La mirada del otro(2013). ${ }^{28}$

En todo el proceso, la mirada es un elemento empático estructurante, como también expresaba una de las víctimas que esperaba encontrar en los ojos humanidad, como se vio en el ejemplo de la tertulia radial. La mirada, poder reconocer al otro, el dolor sufrido y la capacidad de revisar el daño hecho, daban fuerza al programa restaurativo. Esto dialogaba con otras iniciativas del Gobierno vasco orientadas a la construcción de una nueva convivencia vasca como el programa "Víctimas Educadoras" (2010-..) que se realiza en centros escolares llevando el testimonio de víctimas de diversas violencias (del franquismo, violencia policial, ETA) a las aulas, que también pude registrar (Irazusta et al 2017a; b).${ }^{29}$ Este programa emerge al diagnosticarse la ausencia de discusión sobre la violencia local en las aulas vascas, discusión esquivada por curriculos y docentes, y busca promover el reconocimiento del otro. Con el testimonio se fomenta el "aprendizaje de dignidad humana, convivencia y empatía" (Gobierno vasco, programa Adia Adian). No se trata de cualquier víctima, sino de víctimas resilientes dirigidas desde una pedagogía sentimental inscrita en valores universales que despolitizan el debate sobre lo humano, a los sentimientos que son asumidos como emanados de una realidad pura y esencial, sin estar sujetos y mediados por relaciones de poder y procesos históricos específicos (Irazusta et al: 320 y 323).

En estos programas institucionales, las emociones ganan un lugar central siempre que sus portadores eviten enaltecimientos de la violencia y actitudes vengativas. Desde luego, no es nueva esa preocupación por 
garantizar que la emoción posea cierta racionalidad y control, como bien muestra Chakravarti (2008) en el espacio jurídico del post nazismo. Esta autora hace un interesante análisis sobre el contraste entre el uso de lo racional en los juicios históricos de Nuremberg de los años 40 y el ingreso de lo emocional en los juicios de Eichmann de los 60. Destaca cómo en estos últimos, se utilizó el testimonio de la víctima como recurso, pero se priorizó mostrar superación, resiliencia, etc., frente a la parte más dolorida del relato, tal como se hace en ese programa de "Víctimas Educadoras". Así, las emociones no se eliminan, pero se clasifican como unas más aceptables sobre otras (Le Franc 2003). Esto actualiza el estudio de larga duración de Elias (1989) sobre la contribución del "proceso civilizador" y occidental, a la incorporación de la domesticación de lo emocional y de la agresividad que se fue dando paralelo a cambios en la estructura social. ${ }^{30}$ Vale decir que, las demandas institucionales por sentimientos empáticos ignoran lecturas como las de Abu-Lughod (et al 1990) Lutz (1988) o de Coelho (et al 2011; 2017), que al tiempo que reintroducen las emociones en las ciencias sociales, deconstruyen que sean universales.

En estos espacios de construcción de testimonios, la tensión surgía para unos y otros. Así, los relatos son forjados a través de las preguntas y el contexto o "escenario de la memoria" donde son presentados (Feld 2009: 5). En todo testimonio tenemos momentos de selección y omisión de elementos (Welzer et al 2012). Así, si bien esos relatos no se dieron en un espacio jurídico ni policial, compartieron las modulaciones del lenguaje y del cuerpo que regulan esos ámbitos. De esa manera, un guión tácito dirige las posibles respuestas, tal como se dio en otro plano nacional: en la rectificación de los protocolos de la Comisión de Verdad sudafricana. Allí pasaron a orientar los contenidos, los tiempos y las preguntas para ceñirse al evento concreto de violencia y recoger sólo el objeto "violación de derechos humanos" (Wilson 2005; Mamdani 2000). Como muestra Ross (2003) cuando enfatiza la interrelación compleja entre palabras, silencios y elipsis que interaccionan cuando se intenta transmitir experiencias de violencia, donde además operan las diversas comunidades discursivas que pueden habitar las personas (aspectos de honra, lealtad, género y edad, sobre lo que puede ser hablado o no). Aspectos no considerados por la "Comisión de Verdad y Reconciliación" sudafricana, según esta autora que, desde formatos psicoterapéuticos, generó el personaje de las víctimas heridas y violentadas sexualmente, dejando fuera otras dimensiones (Ross 2003: 35 y 50). Situación que también recoge Cinthya Sarti (2011) cuando apunta que en el proceso social de construcción de la violencia, al tiempo que ciertos casos de violencia de género han cobrado gran visibilidad objetivando ciertos afectados 
y agresores, se apagan otras dimensiones de las personas victimizadas y se invisibilizan casos que no ingresan en esos perfiles.

Los programas gubernamentales como el de "Víctimas Educadoras" que mencioné ahora y el de los "Encuentros Restaurativos" (ER) dialogan con estos autores que vengo describiendo. En ambos programas circularon algunas de las víctimas para dar testimonio o para reunirse con los presos. Así, en el programa de los "ER", las expectativas mutuas sobre cómo sería la víctima que viene al encuentro y cómo sería el "etarra", fueron amplias. Por ejemplo, el exetarra que participó de la tertulia comentó que le impactó la entereza manifestada por la víctima, así expresó: "-parecía que ya me había perdonado antes de empezar a hablar". Ese aplomo de la víctima, a veces desarma al victimario que espera encontrar a una víctima enfadada, que lo enfrente. Incluso aquella viuda que entrevisté generó críticas de otras víctimas por su disposición a encontrarse con sus victimarios, y su preocupación por la inserción de su victimario. ${ }^{31}$ Es así que uno y otro se impactan de las reacciones, o la víctima está demasiado tranquila o el culpado escucha con extraña calma: "me escuchó en un silencio sepulcral". Así como se adivinan las palabras no dichas, "estaba arrepentido, aunque no lo dijera, el perdón se sentía en el aire, aunque no lo pidiera" (Lasarte, Carpa Gogora. Gobierno Vasco 2017) como expresó una víctima de ETA, al narrar su experiencia en los "ER", durante un debate que presencié. ${ }^{32} \mathrm{En}$ otro caso puede darse alguna conexión y "aparece la compasión hacia la persona que está en prisión" (Pascual Rodriguez 2013: 136), lográndose uno de los objetivos tácitos de estos "ER".

Por su parte la abogada y coordinadora de los encuentros restaurativos, también experimentó sorpresa cuando entrevistó a los presos de ETA, al estilo de Hanna Arendt ante el nazista Eichman ([1963] 2003) que afirmó, impactando al mundo, que no era el monstruo que se quiso presentar, sino uno más de entre tantos funcionarios del nazismo: más preocupado en escalar en su carrera que en la moralidad de sus actos y los de sus superiores. Incluso Eichmann niega haber matado a alguien, no por ética sino porque: "[... sencillamente no tuv[o] que hacerlo" (Ibid: 18). En el caso de la mediadora, ella tuvo que dejar a un lado su imaginario sobre quien eran los etarras. Descubrió personas de carne y hueso, "rotas por el dolor" que sí asumían que habían matado, como me señaló en la entrevista que mantuvimos (entrevista Pascual Rodríguez septiembre 2013) y, como coloca en su libro:

\footnotetext{
“parece o al menos una así lo piensa, que un terrorista es, por definición, una persona impasible, fría, cauta y distante. [...] Desde mi experiencia personal debo decir que las personas que han participado en los encuentros como vic-
} 
timarios no responden al cliché convencionalmente asumido: no son frías, ni calculadoras. Son personas rotas por el dolor, tremendamente responsables de sus acciones, sinceramente comprometidas con la idea de reparar en la medida de lo posible el sufrimiento causado y esencialmente humanas" (Pascual Rodríguez 2013: 129-130).

Podría decirse que esa humanidad que menciona fue buscada en el cuestionario previo, que diseñaron los expertos que pensaron los "ER", dirigido específicamente a los ejecutores etarras para poder participar de los mismos: "¿Sabía el nombre [de la víctima], la miró a los ojos"? "[...] La primera vez que mató cómo fue? [...] ¿Qué sintió al hacerlo? [...] ?" (Pascual Rodriguez 2013: 130-131). En esas cuestiones además de generar cierta mella moral que deja al preso ante el juicio de su alma, está presente la cuestión de la mirada que recorre todo el proceso (y da título al libro que recoge los "encuentros" como ya mencioné). Ella misma recoge en otro texto que "[...] no se puede matar mirando a los ojos. Matar es tan antinatural que, incluso [...] los pelotones de fusilamiento apuntan a una persona con los ojos vendados, [...] para que los verdugos no se encuentren con la mirada [...de] las víctimas" (Pascual Rodríguez et al 2014: 432 y 433). Vale decir, además, que en ese cuestionario no hubo lugar para palabras esquivas o respuestas ambiguas, desde un inicio la abogada habló con los militantes presos con el verbo "asesinar", según me destacó en una entrevista que le hice (Entrevista Pascual septiembre 2013) ${ }^{33}$.

Además de reunirse con la abogada mediadora, tanto esos ex militantes como las víctimas estuvieron con expertos académicos que influyeron en que intercalaran en sus narrativas conceptos de vulnerabilidad, daño y odio. ${ }^{34}$ Eso también pude advertirlo en eventos donde me crucé con algún exetarra que expresaba: "he vulnerado algunos derechos...", así como a las víctimas. Concretamente, a la víctima que participó de la tertulia que mencioné anteriormente, tuve oportunidad de verla personalmente en unas jornadas donde fue convocada como víctima de terrorismo y donde también estuvo el etarra que publicó su biografía. Allí destacó cómo tuvo una "etapa de odio" que ya abandonó. Ese día reiteró: "-Ahora me doy cuenta de que el odio era un sentimiento natural, y que es lógico que una víctima del terrorismo atraviese una fase en la que, por encima de todo, sienta odio" (IA in Jornadas Buesa 2012: 154). Esa persona lee su propio proceso desde ciertos estudios que señalan esa evolución de emociones como algo esperado, sano, porque si se queda en el odio sería tildada de víctima patológica, resentida (Brudlhom 2008, Minow 1998). Este hombre también participó del programa de Victimas Educadoras, en centros escolares (Irazusta et al 2017 $\mathrm{a} ; \mathrm{b})$ mencionado anteriormente. 
Para cerrar este punto quiero destacar que, si bien no descarto la validez de ese tipo de programas como los "ER" o similares, la economía moral que los sustenta suele esperar determinadas conductas y valores en detrimento de integrar otras lecturas que consideren diferentes actitudes. Me refiero por ejemplo a la posibilidad de poder expresar resentimientos, con doble "s", como reclama Amery (2013), ante las políticas que minimizan la victimización sobre la reconciliación (cf. Brudholm, 2008; Fassin 2013). Para así poder dar debido peso a las actitudes que reaccionan a injusticias y al sufrimiento recibido. Porque el riesgo de esas políticas es simplificar la gran densidad de situaciones y sus efectos en lenguajes abstractos a través de los cuales los expertos, pensadores académicos, y los propios militantes implicados, abstraen los hechos y congelan la diversidad de contextos. Así, como la tendencia es a homologar todo en el dolor independientemente del victimario, dado que todos pueden considerarse víctimas (Le Franc 2010; Salvi 2014), las circunstancias en que sucedieron los eventos se abstraen y se despolitizan (Vinyes 2009; Castillejo-Cuéllar 2009).

\section{Palabras finales}

"Tenemos que conseguir una convivencia normalizada donde se respete y se reconozca al que piensa diferente". [...] Tenemos que empezar a participar en encuentros privados y en actos públicos [...]. abrir espacios de entendimiento y acercamiento entre las personas para facilitar la comunicación que ayude a crear un clima favorable a la superación de las heridas creadas por tantos años de conflicto" (Comunicado del Colectivo de Presos Comprometidos con el Irreversible Proceso de Paz junio, 2011)

El espacio vasco está en plena ebullición de construcción de la gestión de su proceso de paz a través de programas diversos que se instalan sobre un abanico de viejas y nuevas tensiones (gestión de inmigración, de refugiados, revisión de violencias internas). Tensiones que si bien la recorren en diferentes planos acaban reunidas a través de una serie de categorías comunes como convivencia y normalización (Villalón 2016). De este modo esta región ingresa al campo internacional de gestión de post conflicto intentando corregir comportamientos que ampararon o animaron prácticas de violencia. Pero eso que se quiere gestionar es un algo inasible configurado por un mapa complejo de sentimientos y comportamientos que escapan de aquellos naturalizados como positivos o deseables.

Ese mapa se complica por la ampliación del campo victimal actual (Gatti 2017: 18) donde además de la violencia de ETA, se está colocando 
sobre la mesa jurídico legal, como dije antes, tanto la tortura de la violencia policial y estatal (Portela 2016: 165, Etxeberria et al 2016) que coloca a etarras como posibles víctimas; como también a otras víctimas de ETA, los extorsionados y los familiares de etarras que cumplen condena en cárceles lejanas de sus hogares. Todos estos nuevos casos muestran cómo una cosa es ser victimizado y otra, es estar habilitado a ser reconocido como víctima con derecho a expresarse, y también, a querer asumirse como tal, como ya ocurrió en otras naciones (Ross 2003; Aydos 2013). ${ }^{35}$

Presentarse con flores en un cementerio, manifestarse críticamente en programas radiales o en autobiografías sobre sus propias acciones violentas y salirse de la zona comodín de lo político, todo esto moviliza varios elementos de esta configuración de experiencias y narrativas que pugnan por imponerse en ese escenario. En algunos casos emergen la culpa, la vergüenza y los deseos de dignificar parte de su biografía. En otros, se dejan traslucir intentos de equilibrio entre la reevaluación de las acciones de violencia armada que antes defendían y sus lealtades políticas... En definitiva, todos esos movimientos interpelan a varios exetarras que, sin quererlo, se contraponen como "no arrepentidos"; ellos mismos son cuestionados, sus familiares estigmatizados y sobre todo, queda descubierta la comunidad que amparó y defendió esas violencias. Pues al colocar sobre la mesa de la memoria nacional y familiar todas las responsabilidades institucionales, policiales, de grupos armados y de la población local implicada en tolerancias internas y complicidades omitidas (Rothberg 2013, Swartz 2016), se espera contribuir para mostrar otra dimensión de las micropolíticas de reconstrucción nacional. Responsabilidades a las que se refieren incluso algunos exetarras, críticos o no, cuando desean intentar compartir el peso de la responsabilidad con la comunidad, sus vecinos, amigos, colegas o cargos políticos que los animaban a seguir en ETA. La construcción de la convivencia debe atender a todos esos matices.

Añadir al análisis esta red compleja de narrativas, prácticas y sentimientos que operan en una comunidad es requisito obligado frente a los deseos de rápidas transiciones. Así como recordar que, en esas experiencias de manifestar disculpas y reconocimientos, con frecuencia las partes implicadas sólo consiguen ver "sus" víctimas e, incluso, consideran que habría unas más inocentes que otras, dando pie a justificar muertes. Tal como con maestría muestra y denuncia Ruiz Romero (2017) en Colombia, acerca de un pueblo donde sufrieron innúmeras violencias.

En este trabajo he traído ejemplos de otras naciones, no pretendía agotar todas, simplemente he querido mostrar que estas cuestiones, con sus peculiaridades, se viven a lo largo y ancho del mundo. En ese sentido, 
entender cómo se consolidan ciertas disposiciones y complicidades con la violencia, cómo se tensan al verse cuestionadas ya sea por los propios sujetos responsables, como por programas institucionales, todo ello, contribuye a ver las diversas facetas envueltas en esos enfrentamientos (Swartz 2016). Pues, los procesos de post conflicto no son lógicos, ni tienen un proceso lineal hacia un nuevo tiempo ordenado y promisorio (Castillejo-Cuéllar 2017). Así, la relectura de prácticas de violencia, antes justificadas desde lo político, como generadoras de daño y responsabilidades que intentan ser encauzadas con pedagogías institucionales, deja al descubierto la intimidad de las problemáticas locales (Herzfeld 1997). Esto revela sujetos fragmentados en culpas, estigmas, dolores y justificaciones contradictorias. Cuestiones que, en diálogo con otras situaciones, nos permiten reflexionar, e incluso poder recomendar políticas que tengan en consideración otras dimensiones habitualmente censuradas.

En este sentido, destaco la importancia de la investigación para no sólo deconstruir categorías que tanto en el plano social, institucional como académico acaban siendo naturalizadas, sino para además afirmar la necesidad de acompañar todas las dimensiones de estos procesos que albergan experiencias (emocionales, verbales, corporales, cognitivas) de violencia. Así como, participar de eventos donde se describen y/o recuerdan experiencias de violencia, con fines pedagógicos, reparativos y/o "transicionales" que necesitan una cuidada gestión. Como bien coloca Miriam Jimeno (2008), hablar de "experiencia" de violencia, así como ser consciente de su dimensión humana y relacional nos permite evitar esencialismos y abordar diversas situaciones con otra conciencia. Dar cuenta de todos los elementos que operan evitando esencializarlos en un pathos universal, ser resiliente es algo interesante, pero no es la única vía (Améry 2013; Fassin 2003, 2013).

Situaciones como las que he comentado aquí: la salida al ruedo público de personas que tienen delitos, y los asumen; los efectos que generan en sí mismos, entre amigos y familiares sus decisiones; podrían verse enriquecidas con estudios que luego indaguen las narrativas de esos familiares, tales como los hijos o nietos de estas personas. Siguiendo trabajos inspiradores e interesantes como los que han estudiado cómo se transmiten las memorias al interior de familias alemanas del post nazismo (Welzer et al 2012); u otro caso que aborda puntos de vista de hijos de militares, de guerrilleros, de policías, etc., es decir hijos de personas que participaron, activamente, de los años de dictadura y resistencia armada en Argentina tal como analizan Arenes (et al 2016). Existen varios casos de situaciones que décadas después permanecen casi intactas, por tanto, como investigadores sociales, además de mostrar y deconstruir, podemos también movilizar acciones. 
Recebido em: 26/07/2018

Aprovado em: 30/01/2019

Adriana M. Villalón

Pesquisadora posdoc, colaboradora, no PPGAS, IFCH da Unicamp. Egresada do PPGAS/MN, realizou pesquisa de campo na Argentina, Brasil, Pais Basco (Espanha) e, recentemente na África do Sul principalmente nos seguintes temas: Antropologia da violência política e do Estado, antropologia dos processos de construção e gestão de cenários de pós violência, nacionalismos, instituição de limites sociais e territorias; praticas socioespacias; políticas lingüísticas, migratórias, moralidades e emoções. 


\section{Notas}

* Agradeço a Fapesp que financiou a pesquisa deste artigo (processos Fapesp 2013/21800-5 e 2016/22641-6)

1 La comunidad Autónoma Vasca (CAV) -una de las 17 autonomías en que está dividido el estado español desde los 80 tras el fin de cuarenta años de dictadura franquista (1936-1979) - es el territorio oficialmente reconocido como Euskadi o País Vasco desde 1979, ubicado en el nordeste de España y constituido por tres provincias: Guipúzcoa (Gipuzkoa), Álava (Araba) y Vizcaya (Bizkaia). Desde el nacionalismo independentista se consideran también la Comunidad Foral de Navarra (CFN) y tres provincias vasco francesas, en Francia. El nombre para referirse a esos siete territorios vascos es Euskal Herria.

2 ETA fue una organización independentista, creada en 1958, que en mayo 2018 declaró su disolución definitiva, con previos encuentros con agentes de conciliación. En 2011 había anunciado el cese de sus actividades. Fue reprimida ilegalmente por el Batallón Vasco Español, entre los años 1975- 1981, y el GAL (grupos Antiterroristas de Liberación, creado por el gobierno del PSOE durante 1983-1987. Esas violencias fueron contempladas en las leyes de 2007 y 2011 como "terrorismo y vulneración de derechos humanos". https://elpais.com/politica/2018/05/03/actualidad/1525336524_523980.html

3 Se consolidó en unas 30 personas que abandonan críticamente ETA hacia el año 2010, durante el gobierno del PSOE (2004-2011). Estas fueron concentradas en la cárcel vasca de Nanclares de Oca, lo cual llevó a que sean conocidas como "la vía Nanclares", y como favorecidos frente a otros presos que sufren la dispersión en diversas cárceles de España, alejados de sus hogares, lo cual denuncian sus familiares a través de continuas manifestaciones. De entre aquellas personas críticas, que tienen matices diversos sobre la intensidad de su ruptura, surge en el 2010 un subgrupo de 8 personas que profundizan la ruptura y se autodenominan: "presos comprometidos con el irreversible proceso de paz" que animan tanto a políticos, como etarras a dar pasos en la autocrítica y a romper con la cúpula de ETA. (Cf. El País 24-09-2011 "Texto Del Colectivo de Etarras de Nanclares".

4 Me referiré a estos Encuentros Restaurativos tanto en forma extensa como abreviada: "ER".

5 Vale destacar que el Gobierno vasco encargó a una comisión de expertos, en el 2011, la elaboración de un registro de vulneraciones a los derechos humanos, procedentes exclusivamente del estado o funcionarios de gobierno, ocurrida en su territorio entre 1960 y 2013. Fue elaborado por el Instituto Vasco de Criminología (IVC) (Etxeberria 2016). Es interesante notar que, sobre la violencia policial e institucional si bien ha habido alguna sentencia condenatoria, quien ha llevado adelante esta investigación antes que el Estado español, ha sido el gobierno vasco. Luego emitió el Decreto 107/2012, para atender casos de tortura ocurrida entre 1960 y 1978, por parte de fuerzas policiales o del Estado. (Cf. Diario ABC 3-12-2012 "El gobierno vasco reconoce a dos etarras como víctimas de la violencia política"). 
6 A partir de 1988 comienza una actividad legislativa tanto a nivel autonómico como estatal a favor de las víctimas del terrorismo. El gobierno vasco emite la "Ley 4/2008, de Reconocimiento y Reparación a las Víctimas del Terrorismo".

7 Es conocido el trabajo de Jean-Michel Chaumont (2002) sobre el período de pos guerra y de víctimas del nazismo, que analiza las controversias históricas ocurridas en el campo de asociaciones de víctimas, diversas, por ganar reconocimiento, entre otras cuestiones. Otros sujetos, décadas después, se sumarán a esa pugna: alemanes, no judíos, que en los 90 empiezan a reclamar también el estatuto de víctimas (por los bombardeos norteamericanos de los 40). Demandas que antes no era posible colocar en el espacio público, como bien analiza Huyssen (2014). Situaciones similares ocurrieron en otros escenarios nacionales, como señala Virginia Vecchioli (2001) para Argentina, cuando familiares de militares reclamaron ser reconocidos como víctimas siendo la tónica englobarlos como victimarios.

8 En otro trabajo destaqué la llegada de las categorías de normalización y convivencia a la gestión del proceso de paz. Categorías nativas con fuerte presencia local en otros procesos, tales como la "normalización de la política lingüística, y la gestión de la convivencia para reducir roces entre locales e inmigrantes (Villalón 2016: 538). Temáticas que estudié muy bien cuando trabajé en la administración pública local con mediación y gestión sobre cuestiones de población inmigrada, llegada a partir del 2000, calificada como no europea, no comunitaria, (Cf Villalón 2009; 2011).

9 Fue impulsado en por la "La Dirección de Víctimas del Terrorismo del Gobierno Vasco [...] con el apoyo del Ministerio del Interior, a través de la entonces Secretaria General de Instituciones Penitenciarias" (Pascual Rodríguez 2014: 432), durante el gobierno del PSOE en el Estado y en el País Vasco (2009-2011). Pero en el gobierno siguiente del Partido Popular (2012-2017) los encuentros fueron suspendidos. Luego aquélla direcciónn de víctimas se redenominó como Dirección de Víctimas y Derechos Humanos que, a su vez, creó en el 2013 la Secretaría de Paz y convivencia. . http:// www.euskadi.eus/gobierno-vasco/paz-convivencia/

10 "El exetarra Ibon Etxezarreta homenajea a una víctima en cuyo asesinato participó" (ABC 2014 EFE). Todo tipo de movimiento de estos hombres y mujeres tuvo impacto mediático, con excepción de los diarios más afines a la llamada "izquierda abertzale", que defiende el independentismo vasco y con muchas heterogeneidades en su interior en su respaldo a lo que fue la actividad de ETA. En este caso el Diario $\mathrm{ABC}$ es considerado conservador y monárquico; otros diarios que sacan muchas notas sobre estos eventos son El País (del grupo Prisa), El Mundo, de centro derecha, El Diario Vasco, considerado liberal, incluso uno de sus directores financieros fue asesinado por ETA en el 2001.

\section{Cf nota $n^{\circ} 4$}

12 Con esto me refiero tanto a grupos civiles armados que se valen de la violencia para lo que consideran sus objetivos políticos (como las FARC, el IRA, etc.) o de otro tipo (al estilo de la "mafia italiana" u otros criminales), como algunos de tipo institucional (como paramilitares, policías, etc.) que también usan recursos 
extrajudiciales para eliminar quienes se salgan de ciertos pactos y lealtades. Pero desde luego ello requiere un análisis más profundo para apreciar las particularidades de cada uno.

13 También una exetarra Carmen Gisasola que salió en libertad en el 2014, tras más de 20 años de prisión, publicó una novela, en euskera, "Gaur sortzi" (2012) que escribió en reclusión. Trata sobre una madre cuya hija entra a la lucha armada). (Cf. El País 23-10-2012. "La exetarra Gisasola..."). No conseguí entrevistar a esta mujer, ni a su pareja (ambos miembros del subgrupo crítico), tras una breve charla telefónica ella expresó desconfianza y estar muy quemada con las tergiversaciones hechas por la prensa.

14 Gudari en euskera (lengua vasca) significa "soldado" y es el nombre que se autoatribuyen los integrantes de ETA.

15 Las ekintzak, que en lengua vasca significa acciones, es la palabra utilizada por integrantes de ETA y simpatizantes para referirse, y, agrego, no nombrar, a los asesinatos y atentados; así como también se usa jerga militar como "ejecuciones".

16 Cf. Nota 16.

17 La situación de Colombia merece un artículo aparte, destaco aquí que este país se encuentra en situación de pos conflicto hace décadas, con la particularidad de que, a diferencia de otras naciones "post", ha iniciado varios procesos internos de gestión de la violencia (responsables, victimas, ex responsables..) muchos años antes de que se considere finalizado. Por ejemplo, ya entre .."2003 a 2007 se han entregado al Estado poco menos de 45.000 combatientes, a quienes se conoce como "desmovilizados" [...]" (Jimeno 2008: 271-272).

18 Ese campesino le dijo al autor: "Que la comisión les ayude para que los perdonen desde la comunidad vecina. Que entiendan que muchos fuimos obligados o que lo hicimos sin saber mucho, yo mismo fui, niño era, a esa batalla, cuando les matamos dirigidos por Sendero. Desde allí nos odian y estamos arrepentidos" (Agüero 2015: 48).

19 Como es sabido parte de la comisión de la verdad sudafricana, en su sección de amnistía dio esa posibilidad de no ser condenados a los responsables (institucionales, policiales) a cambio de que confiesen la verdad y asuman sus crímenes (Cf. Wilson 2005).

20 La Cadena SER ("Sociedad Española de Radiodifusión") es una cadena generalista y de ámbito nacional, que cuenta con numerosos oyentes, Pertenece al consolidado grupo PRISA Radio.

http://cadenaser.com/programa/2014/07/13/a_vivir_que_son_dos_ dias/1405209013_850215.html

21 Igual que en otro espacio como el colombiano, algunos hablan de "actos de guerra" como forma de justificar muertes y minimizar responsabilidades como analiza Ruiz Romero (2017: 17). 
22 Algo parecido a lo que un par de décadas atrás narraba otro joven etarra, tras matar a otro empresario "lo peor es que acabas haciendo amistad y entonces..." (Zulaika 1990: 117).

23 El marido de esta mujer fue asesinado por ETA en el año 2000.

24 Esta intimidad ya la había retratado Zulaika (1990) más de veinte años atrás, cuando intentaba comprender la "violencia política vasca" a partir de seis muertes, significativas, que habían ocurrido en su pueblo natal. La peculiaridad era que matadores y víctimas, no sólo fueron algunos de sus colegas de la infancia y adolescencia, sino que además habían sido amigos entre sí. Otro sonado caso fue el de una ex integrante de ETA cuando su matador, en plenas fiestas de su pueblo, antes de dispararle la llama por su nombre "Yoyes!"; al girarse reconoce a su ex colega que le dispara frente a su hijo pequeño. Este caso de Yoyes fue muy singular, porque si bien en la transición de los 80 hubo muchos otros integrantes que renunciaron a ETA, Aretxaga (2005: 158) pregunta ¿̇por qué la mataron sólo a ella? y responde que era un caso paradigmático que reunía los roles de "héroe, traidora, mártir y madre".

25 Describe a lo largo de 500 páginas, ambientas en el País Vasco, cómo se quiebra la amistad entre dos familias, dos mujeres (y toda una red de personas vinculadas), cuando el marido de una es asesinado por el hijo de su amiga de toda la vida.

26 Dirigida por Milcho Manchevski es un drama sociopolítico, con duros desencuentros familiares, en el contexto de la Guerra de los Balcanes, donde viejos amigos y amores quedan enfrentados como bosnios y macedonios.

27 "Conversaciones imposibles. La tarde en que Maixabel se citó con el etarra que asesinó a su marido" (El Mundo 20-9-2015).

28 Estos "ER" estaban informados por concepciones de justicia restaurativa, que entre otros aspectos buscan el aspecto humano del preso, rasgo analizado en su tesis de doctorado por esta abogada y mediadora que coordinó ese programa de encuentros (Pascual Rodríguez 2011).

29 El programa de "víctimas educadoras" también es impulsado por el Gobierno vasco, está dirigido a estudiantes, escolares y universitarios, las víctimas dan testimonio evitando generar sentimientos de venganza u odio en los oyentes. Comenzó hacia el 2010 con el PSOE, luego a partir del 2013 con PNV pasó a llamarse Adi Adian. Para una descripción etnográfica de este programa cf. Irazusta et al $(2017 \mathrm{a}, \mathrm{b})$. Se recoge el resultado de una investigación dirigida por Gabriel Gatti (2017) Mundos de Victimas.

30 Para otros análisis del control de la emoción como sinónimo de civilidad cf.Jimeno (2009) y Gatti (2010).

31 Un ejemplo extremo es el título de esta nota de prensa: "Maixabel Lasa, la viuda de ETA que pide trabajo para los asesinos de su marido" https://www.elmundo.es/papel/historias/2018/04/28/5ae34070e5fdeaf5698b4684.html. (El Mundo 28-4-2018). 
32 También organizado por Gogora [hacia la memoria], Intituto de la Memoria, la Convivencia y los Derechos Humanos, del gobierno vasco, creado en el 2013. Consiste en la colocación de una carpa ambulante que va recorriendo los municipios, dentro de la cual se exhiben videos y mesas redondas con testimonios de víctimas (de los tres tipos de violencias que identifican: del franquismo, de ETA y policial), entre otras actividades. Acompañé esta exposición en tres municipios diferentes.

33 Para ver otro análisis de interrogatorios a victimarios cf. Payne (2009).

34 Además de reunirse con víctimas en la prisión vasca de Nanclares de Oca, participaron en los "talleres de convivencia" (2011), que consistieron en charlas con diversas figuras tales como políticos, víctimas y académicos.

35 Esa autora muestra como las "vítimas da ditadura militar" em Brasil demoraram en ser vistas y sentirse como vítimas. "[...] Durante esse primeiro momento do regime ditatorial, apesar de a tortura em si ser vista como uma prática ilegítima pela sociedade em geral, não se tinha ainda como falar em 'vítimas' e 'opressores'" (Aydos et al. 2013: 383 e 398).

\section{Errata Mana 25(1)}

No artigo EL CUERPO CULPABLE EN EL ESPACIO PÚBLICO: DE DISIDENCIAS, TRAICIONES Y ARREPENTIMIENTOS EN LA CONVIVENCIA VASCA, com número DOI http://dx.doi.org/10.1590/1678-49442019v25n1p189, publicado no periódico Mana. Estudos de Antropologia Social, 25(1):189-219, páginas 189 e 207: Onde se lia:

"Adriana Villalón"

Leia-se:

"Adriana M. Villalón"

Na página 208, foi acrescentada a seguinte nota:

"* Agradeço a Fapesp que financiou a pesquisa deste artigo (processos Fapesp 2013/21800-5 e 2016/22641-6)" 


\section{Bibliografía}

ABU-LUGHOD, Lila e LUTZ, Catherine (orgs.). 1990. Language and the Politics of Emotion. Cambridge: Cambridge University Press.

AGÜERO, José Carlos, 2015, Los rendidos: Sobre el don de perdonar. Lima: IEP.

ALCEDO MONEO, Miren. 1996. Militar en ETA. Historias de vida y muerte. Haranburu: San Sebastian.

AMÉRY, JEAN. 2013 [1963]. Más allá de la culpa y la expiación. Tentativas de superación de una víctima de la violencia. Valencia: Pre-textos.

AYDOS Valéria; FIGUEIREDO. César 2013. "A construção social das vítimas da ditadura militar e a sua ressignificação política". Interseções, 1 (2): 392-416.

ARAMBURU Fernando. 2016. Patria. Tusquets. Barcelona.

ARENDT, Hannah 2003 [1963] Eichmann in Jerusalem. Un estudio acerca de la banalidad del mal. Lumen, Barcelona.

ARENES, Carolina y Pikielny, Astrid. 2016. Hijos de los 70. Historia de la generación que heredó la tragedia Argentina. Buenos Aires: Sudamericana.

ARETXAGA, Begoña. 2005. States of Terror: Begoña Aretxaga's Essays. Reno: University of Nevada.

BARREIRA, César. 1998. Crimes por encomenda: violência e pistolagem no cenário brasileiro. Rio de Janeiro: Relume Dumará: Núcleo de Antropologia da Política.

BLATZ, Craig. 2009. "Government Apologies for Historical Injustices". Political Psychology, 30 (2): 219-241.

BORGES, Jorge Luis. [1944] 2010. La muerte y la brújula, Buenos Aires, Emecé

BRUDHOLM, Thomas. 2008. Resentment's virtue : Jean Améry and the refusal to forgive. Temple University Press: USA.

CASTILLEJO-CUÉLLAR，Alejandro. 2013. "Voces [en la cabeza]: espacialidad, mediaciones teletecnológicas y las verdades caleidoscópicas en el proceso de Justicia y Paz en Colombia", Papeles del CEIC, 1.

. 2017. La ilusión de la justicia transicional: perspectivas críticas desde América Latina y Sudáfrica. Colombia: Uniandes

. 2009. Los archivos del dolor: Ensayos sobre la violencia y el recuerdo en la Sudáfrica contemporánea. Colombia: Uniandes.

CHAKRAVARTI, Sonali. 2008. "More than 'Cheap Sentimentality': Victim Testimony at Nuremberg, the Eichmann Trial, and Truth Commissions". Constellations 15 (2): 223-235.

CHAUMONT, Jean-Michel. 2002. La concurrence des victimes: Génocide, identité, reconnaissance. Paris: La Découverte.

2000. « Du culte des héros à la concurrence des victimes » Criminologie, 33 (1): 167-183.

COELHO, Maria claudia; REZENDE, Claudia Barcellos. 2011. (org.) Cultura e sentimentos: ensaios em antropologia das emoções. Rio de Janeiro: Contra Capa / faperj.

COELHO Maria Claudia; Susana DURÃO. 2017. "Introdução ou Como Fazer Coisas com Emoções". In: Coelho \& Durão Dossiê Emoções, Política e Trabalho - estudos em antropologia das emoções, INTERSEÇÕES, 19 (1): 44-60

DAS, Veena. 1999. "Fronteiras, violência e o trabalho do tempo: alguns temas wittgensteinianos". Revista Brasileira de Ciências Sociais, São Paulo, 14 (40): 31-42 
ELIAS, Norbert. 1989 [1939]. El Proceso de la Civilización. Investigaciones Sociogenéticas y Psicogenéticas. México: Fondo de Cultura Económica

ETXEBERRIA, Francisco; BERISTAIN Carlos Martín y PEGO, Laura. 2016. Proyecto de investigación de la tortura en el País Vasco (1960-2013) Instituto Vasco de Criminología. Memoria-Resumen de la actividad realizada. Bilbao: Secretaría General para la Paz y la Convivencia.

FASSIN, Didier. 2013. "On Resentment and Ressentiment The Politics and Ethics of Moral Emotions Source". Current Anthropology, 54 (3): 249267.

.2003. La Patetización del Mundo Ensayo de Antropología Política del Sufrimiento (http://132.248.35.1/cultura/2003/ponencias-2/wpon4.html

FELD, Claudia. 2009. "Entre la visibilidad y la justicia: Los testimonios televisivos de represores en la Argentina". Revista Encuentros Uruguayos, Año II, 2: 42-57.

GATTI Gabriel (Coord.). 2017. Un mundo de víctimas. Antrophos: Siglo XXI.

. 2010. "O detidodesaparecido: catástrofe civilizacional, desmoronamento da identidade e linguagem", Revista Crítica de Ciências Sociais [Online], 88. URL : http://rccs.revues. org/77

GISASOLA, Carmen. 2012. Gaur sortzI. Alberdania: Donostia

HERZFELD, Michael. 1997. Cultural Intimacy. Social Poetics in the NationState. London: Routledge

HOYOS, Juan Felipe. 2011. Capitales para la guerra y el testimonio en un contexto transicional. Etnografía de la producción narrativa de desmovilizados. Tesis maestría. Universidad Nacional de Colombia.

IRAZUSTA, Ignacio; RODRIGUEZ MAESO, Silvia; VILLALÓN, Adriana
M. 2017a. "'Victims as Educators': Sentimental Education in a PeaceBuilding Context". Journal of Human Rights Practice, 9 (1): 50-67.

IRAZUSTA, Ignacio; RODRIGUEZ MAESO, Silvia; VILLALÓN, Adriana M. 2017b. Las víctimas en la escuela vasca: iniciativas políticas para una 'educación sentimental', in Gabriel Gatti (org.), Un mundo de víctimas. Barcelona: Anthropos, 309-330.

JIMENO, Myriam. 2008. "Lenguaje, subjetividad y experiencia de la violencia", en Veena Das Sujetos del dolor, agentes de dignidad. FCo Ortega, editor. Bogotá: Pontificia Universidad Javeriana et al.

. 2004. Crimen pasional: contribución a una antropología de las emociones, Bogotá : Universidad Nacional de Colombia.

KLEINMAN, Arthur; DAS, Veena.; LOCK, Margaret. 1997. Social suffering. Berkeley. University of California Press.

LUTZ, Catherine. 1988. Unnatural emotions everyday sentiment on a Micronesian atoll (Chicago and London: University of Chicago Press.

MAMDANI Mahmood. 2001. When Victims Become Killers. Princeton University Press and copyrighted, Princeton, University Press.

2000. "The Truth According to the TRC", in Ifi Amadiume and Abdullahi An-Na'im (orgs) The Politics of Memory: Truth, Healing and Social Justice, Zed Books, London.

MAUSS, Marcel. [1950] 1979. "Efectos físicos ocasionados en el individuo por la idea de la muerte sugerida por la colectividad". In: M. Mauss, Sociologia y antropologia. Tecnos: Madrid. pp. 293-307.

MINOW, Martha. 1998. Between vengeance and forgiveness: Facing 
history after genocide and mass violence. Beacon Press

OLAYA GOEZ, Paula. 2018. Ser un (des) vinculado en el 'fin del conflicto armado' colombiano: una cartografía de la desvinculación, texto Prova de qualificação, Ciencias Socias, IFCH, Unicamp.

PASCUAL RODRÍGUEZ. Esther. 2014. "Reflexiones desde los Encuentros Restaurativos entre Víctimas y Condenados por Delitos de Terrorismo". Oñati Socio-Legal Series, 4 (3): 427-442.

(org). 2013. Los ojos del Otro: encuentros restaurativos entre víctimas y ex miembros de la organización terrorista ETA. Sal Terrae: Madrid.

2011. La Mediación en el Sistema Penal: Propuestas para un Modelo Reparador, Humano y Garantista. Tesis doctoral. Universidad Complutense de Madrid.

PAYNE, Leigh. 2009. Confesiones perturbadoras. Ni verdad ni reconciliación en las confesiones de violencia de Estado. Uniandes, CESO: Bogotá.

POLLAK Michael, 2006. Memoria, olvido, silencio. La producción social de las identidades frente a situaciones límite. Edcs, $\mathrm{Al}$ Margen: La Plata.

PORTELA, Edurne. 2016. El eco de los disparos. Galaxia Gutenberg, S.L., Barcelona,

REKARTE, Iñaki. 2015. Lo más difícil es perdonarse a uno mismo. Península, Madrid.

ROTHBERG Michael. 2013. 'Multidirectional Memory and the Implicated Subject', In L. Plate and. A. Smelik (eds.), Performing Memory and art popular, 39-58. Routledge: New York

ROSS Fiona. 2003. Bearing Witness. Women and Truth And Reconciliation Commission In South Africa. London, Pluto Press.
RUIZ ROMERO, Gabriel. 2017. "Tres veces en la plaza: Escenificación de una ceremonia estatal de perdón público por actos de violencia paramilitar en Colombia". AIBR. Revista de Antropología Iberoamericana, 12 (1): p. 9-30.

SALVI, Valentina. 2014. "'Todos somos víctimas'. Transformaciones en la narrativa de la 'reconciliación nacional' en la Argentina". In: J. L. Lanata (org.) Prácticas genocidas y violencia estatal en perspectivas transdiciplinar. San Carlos de Bariloche: IIDyPCa-CONICET.

SARTI, Cynthia. 2011. "A vítima como figura contemporânea." Caderno CRH, 24(61): 51-61.

SWARTZ, Sharlene. 2016. Another Country: Everyday Social Restitution, Cape Town: HSRC BestRed.

THEIDON, Kimberly; BETANCOURT, Paola Andrea. 2006. "Transiciones conflictivas: combatientes desmovilizados en Colombia". Análisis Político 58: 92-111.

THEIDON, Kimberly. 2004. Entre prójimos. El conflicto armado interno y la política de la reconciliación en el Perú. Lima: IEP (Estudios la Sociedad Rural, 24).

VECCHIOLI, Virginia. 2001. "Políticas de la Memoria y Formas de Clasificación Social. ¿Quiénes son las 'Víctimas del Terrorismo de Estado' en la Argentina?". In: B. Groppo y P. Flier (org). La Imposibilidad del Olvido. Recorridos de la Memoria en Argentina, Chile y Uruguay. Ed. Al Margen: Argentina. La Plata. pp. 83- 102.

VILLALÓN, Adriana María. 2016. "Construyendo la vasquidad: de estímulos, convivencias y límites lingüísticos". Revista Mana MANA 22(2): 519-550. . 2011. Manteniendo el fuego: mecanismos de construcción de espacios y 
límites de la vasquidad. Tesis de Doctorado, PPPGAS,MN, Universidade Federal do Rio de Janeiro, Brasil. . 2009. "Espacio escolar y proyectos nacionales: la gestión de la inmigración en el País Vasco". In: L. Cachón y M. Laparra (org.). Inmigración y Políticas Sociales. Barcelona: Bellaterra. pp 217-237.

VINYES, Ricard. 2009. "Sobre víctimas y vacíos: ideologías y reconciliaciones; privatizaciones e impunidades". In: A. Domínguez Rama (org). Enrique Ruano: Memoria viva de la impunidad del franquismo. Madrid: Editorial Complutense. pp. 255-272.

\section{Jornadas Seminarios}

XI Seminario Fernando Buesa. XI. Fernando Buesa Mintegia. 2014. Políticas de memoria / Qué, cómo y para qué recordar. Oroimen politikak/Zer, nola eta zertarako gogoratu. Fundación
WELZER, Harald, MOLLER Sabine, TSCHUGGNALL Karoline. 2012. Mi abuelo no era nazi. El nacionalsocialismo y el Holocausto en la memoria familiar. Prometeo, Buenos Aires.

WIEVIORKA Michel. 2003. "L'émergence des victimes » Sphera publica, 3: 19-38.

WILSON, Richard A. 2005. The Politics of Truth and Reconciliation in South Africa. Legitimizing The Post-Apartheid State, Cambridge University Press United Kingdom.

ZULAIKA, Joseba. 1990. Violencia Vasca, Metáfora y Sacramento, Nerea, Madrid.

Fernando Buesa 21 y 22 de noviembre de 2013- BLANCO FUNDAZIOA.

Evento Gobierno Vasco 2017 "Carpa Gogora", Lasarte, exposición itinerante Memoria Plaza.

\section{Documentos}

Comunicado del Colectivo de Presos Comprometidos con el Irreversible Proceso de Paz junio, 2011.

\section{Noticias de prensa}

Deia 27-06-2017 "El informe sobre la tortura en Euskadi identifica 4.009 casos desde 1960" http://www.deia. com/2016/06/27/politica/euskadi/el-informe-sobre-la-tortura-en-euskadi-identifica-4009-casos-desde-1960[consultado julio 2017]

Diario ABC 30-7-2014 "El exetarra Ibon Etxezarreta homenajea a una víctima en cuyo asesinato participó" https://www.abc.es/espana/20140730/ abci-juan-maria-jaureguien-etarra-201407301241.html

Diario ABC 3-12-2012 “El gobierno vasco reconoce a dos etarras como víctimas de la violencia política" http://www. abc.es/espana/20121203/abci-gobierno-vasco-victimas-201212031957. html [consultado julio 2017).

El Mundo 28-4-2018 "Maixabel Lasa, la viuda de ETA que pide trabajo para los asesinos de su marido" https://www. elmundo.es/papel/historias/2018/04/ 28/5ae34070e5fdeaf5698b4684.html

El Mundo 20-9-2015 "Conversaciones imposibles. La tarde en que Maixabel se citó con el etarra que asesinó a su marido". http://www.elmundo.es/es pana/2015/09/20/55fe0c5f46163fb01 f8b457c.html [consultado julio 2017) 
El País 5-3-2018 "ETA anuncia su disolución. La banda comunica el 'final de su trayectoria' y que 'ha desmantelado totalmente sus estructuras'". https://elpais. com/politica/2018/05/03/actualidad/1525336524_523980.html [consultado julio 2017]

El País 23-10-2012. "La exetarra Gisasola escribe una novela a favor de la convivencia en Euskadi" http://www. alberdania.net/intranet/upload/docs/ recortes/doc_882.pdf [consultado julio 2017].

El País 24-09-2011 "Texto Del Colectivo de Etarras de Nanclares: 'Es Hora De Abordar La Reconciliación'" https://elpais.com/diario/2011/09/24/ espana/1316815205_850215.html [consultado julio 2017].

\section{Entrevistas}

Entrevista F.E, marzo 2017

Entrevista I.R, marzo 2017

Entrevista M.A, febrero 2017

Entrevista E. Pascual Rodríguez septiembre 2013 


\section{EL CUERPO CULPABLE EN EL} ESPACIO PÚBLICO: DE DISIDENCIAS, TRAICIONES Y ARREPENTIMIENTOS EN LA CONVIVENCIA VASCA

\section{Resumen}

¿Cómo se reconfiguran lealtades y narrativas de heroísmo ante rupturas y reflexiones de ex militantes armados que reconocen sus crímenes? ¿Cómo interaccionan en sus comunidades las diversas partes implicadas, directa o indirectamente, en los conflictos? Este artículo analiza las narrativas y emociones en tensión en torno a la figura de ex militantes de ETA que abandonaron esa organización, a partir de una ruptura crítica con sus propios actos de violencia, declarándose disidentes. Como parte de eso decidieron reunirse con los familiares de las víctimas que generaron, asumir responsabilidades civiles y, lo principal, hacer pública su ruptura. Pero esos movimientos tuvieron resonancias conflictivas entre sus allegados, vecinos y medios de comunicación que leyeron esas disidencias como arrepentimientos o traiciones. El texto se basa en registros etnográficos sobre la situación de revisión de violencias realizadas y sufridas en el actual proceso de paz vasco gestionado por la Secretaría de Paz y convivencia, del Gobierno vasco (España).

Palabras clave: Ex Integrantes de ETA, Arrepentidos, Encuentros Restaurativos, Tensiones, Convivencia.

\section{THE GUILTY BODY IN PUBLIC SPACES: OF DISSIDENCE, BETRAYAL, AND REGRET IN BASQUE COEXISTENCE}

\section{Abstract}

How are loyalties and narratives of heroism reconfigured by the ruptures and reflections of former armed militants who recognize their crimes? How do the various parties involved, directly or indirectly, interact in conflicts in their communities? This article analyzes the narratives and emotions in tension around the figure of former ETA militants who left that organization, from a critical break with their own acts of violence, declaring themselves dissidents. As part of that they decided to meet with the relatives of the victims they generated, assume civil responsibilities and, principally, make public their breakup. But those movements had conflicting resonances between their relatives, neighbors and the media that read such dissidences as regrets or betrayals. The text is based on ethnographic records on the current situation of review of violence committed and suffered in the current Basque peace process managed by the Basque government's Secretariat of Peace and coexistence (Spain).

Keywords: Former ETA Militants, Regrets, Restaurative Encounters, Tensions, Coexistence. 


\title{
O CORPO CULPADO NO ESPAÇO PÚBLICO: SOBRE DISSIDÊNCIAS, \\ TRAIÇÕES E ARREPENDIMENTOS NA CONVIVÊNCIA BASCA
}

\begin{abstract}
Resumo
De que modo se reconfiguram lealdades e narrativas de heroísmo diante de rupturas e reflexões de ex-militantes armados que reconhecem seus crimes? Como interagem em suas comunidades as diversas partes envolvidas, direta ou indiretamente, nos conflitos? Este artigo analisa as narrativas e as emoções em tensão em torno das figuras de exmilitantes do ETA que abandonaram esta organização a partir de uma ruptura crítica com seus próprios atos de violência, declarando-se dissidentes. Como parte disto, decidiram reunirse com os familiares das vítimas que geraram, assumir responsabilidades civis e, o principal, tornar pública sua ruptura. Contudo, estes movimentos tiveram ressonâncias conflituosas entre seus próximos, vizinhos e meios de comunicação, que leram tais dissidências como arrependimentos ou traições. O texto baseia-se em registros etnográficos sobre a situação de revisão de violências realizadas e sofridas no atual processo de paz basco gerido pela Secretaria de Paz e Convivência do governo basco (Espanha).
\end{abstract}

Palavras-chave: Ex-integrantes do ETA, Arrependidos, Encontros restaurativos, Tensões, Convivência. 